\title{
Fate of the gold and the thiomalate part after intramuscular administration of aurothiomalate to mice
}

\author{
EGIL JELLUM, EIMAR MUNTHE, GRO GULDAL, AND JAN AASETH \\ From the Institute of Clinical Biochemistry, Rikshospitalet, Oslo 1, and Oslo Sanitetsforening, Rheumatism \\ Hospital, Oslo 1, Norway
}

SUMmARY Double isotope-labelled aurothiomalate $\left({ }^{195} \mathrm{Au}-{ }^{14} \mathrm{C}\right.$-thiomalate) has been administered to mice, and the excretory fate and tissue distribution have been studied. The results show that the gold and the thiomalate separate in vivo resulting in protein-bound gold and release of free thiomalate. About half of this thiol is excreted in the urine during the first day, and the remaining half is bound to tissue membranes and cells. Although thiomalate penetrates cellular membranes slowly in vitro. the compound is found in all organs, mostly in the liver and the kidneys, after administration of aurothiomalate. Separation of the gold moiety from its thiol carrier also takes place in man. This explains the finding of free thiomalate in the urine of patients receiving aurothiomalate intramuscularly. As thiomalate has now been shown to possess penicillamine-like biological activities it is suggested that at least part of the antirheumatic effects of aurothiomalate may be due to the thiol carrier being released in the body.

Several studies in vivo and in vitro have shown that the antirheumatic drug aurothiomalate (Myocrisin) in serum is bound mainly to albumin (McQueen and Dykes, 1969; Danpure, 1974; Danpure, 1976; Lorber, 1977). This conclusion is based upon analyses of the gold moiety of the drug, whereas little attention has been paid to the supposed inert carrier molecule, thiomalate. Recently we (Jellum et al., 1977) demonstrated that the interaction of serum proteins with aurothiomalate in vitro results not only in binding of the gold to the proteins but also in a concomitant release of free thiomalate (see also Danpure, 1976).

In the present studies double isotope-labelled aurothiomalate has been administered to experimental animals, and the excretory and metabolic fate and tissue distribution of both the gold moiety and the thiomalate part of the drug have been followed. The results show that protein-bound gold and free thiomalate are present also in vivo. Part of the latter thiol is excreted in the urine, and part is bound to tissue membranes and cells.

These observations are of particular interest in view of the increasing attention given to thiols as

Accepted for publication 30 April 1979

Correspondence to Dr E. Jellum, Institute of Clinical Biochemistry, Rikshospitalet, Oslo 1, Norway. antirheumatic agents (Multi-Centre Trial Group, 1973; Munthe, 1977; Lyle and Kleinman, 1977; Feltkamp, 1979) and the finding that thiomalate is not an inert carrier but has profound biological effects in in-vitro systems (Arrigoni-Martelli et al., 1978).

\section{Materials and methods}

RADIOLABELLED COMPOUNDS

Myocrisin labelled in the gold moiety $\left({ }^{955} \mathrm{Au}-\right.$ thiomalate) and ${ }^{14} \mathrm{C}$-thiomalate were supplied by May and Baker, Dagenham, London. Equilibration of the 2 compounds in a mixture resulted in exchange of radiolabels, and after purification by preparative thin-layer chromatography, double isotope labelled Myocrisin $\left({ }^{195} \mathrm{Au}\right.$ in the gold part and ${ }^{14} \mathrm{C}$ in the thiomalate moiety) was obtained.

${ }^{14} \mathrm{C}$ activity of urine, serum, and tissue homogenates was counted in a Packard Tri-Carb liquid scintillation spectrometer, using Packard Dilusolve scintillator cocktail. All results were corrected for quenching. Determination of ${ }^{14} \mathrm{C}$ in the presence of ${ }^{195} \mathrm{Au}$ was carried out by first counting ${ }^{195} \mathrm{Au}$ activity in a gamma counter (Nuclear Chicago, Inc., USA) followed by counting of the sample in the liquid scintillation counter. From the total activity $\left({ }^{195} \mathrm{Au}\right.$ 
$+{ }^{14} \mathrm{C}$ ) obtained in the latter were subtracted the counts due to the gold isotope, leaving a net activity due to ${ }^{14} \mathrm{C}$.

\section{ANIMAL EXPERIMENTS}

Female mice, NMRI strain, weighing $20 \pm 1 \mathrm{~g}$ were given single, intramuscular injections of the radiolabelled compound $(0 \cdot 1 \mu \mathrm{Ci} ; 20 \mu \mathrm{g}$ of substance corresponding to $1 \mathrm{mg} / \mathrm{kg}$ body weight, dissolved in $0.1 \mathrm{ml}$ of $0.9 \% \mathrm{NaCl}$ ). Faeces and urine from the animals were quantitatively collected in special metabolic cages. Organ distribution of the radiolabels were determined 6,12 , and 20 hours after injections of the drug. The animals were killed by decapitation and brain, kidney, liver, spleen, lung, muscle, and skin samples as well as blood, urine, and faeces were analysed as described above.

In some experiments expiratory air was collected after administration of the labelled compound. The animal was placed horizontally in a specially designed plastic cylinder, and the expired $\mathrm{CO}^{2}$ was quantitatively collected in a gas trapping flask and subsequently counted in the scintillation spectrometer.

\section{IN-VITRO EXPERIMENTS}

Penetration of aurothiomalate, thiomalate, and penicillamine through cellular membranes was studied by incubating human erythrocytes and isolated rat liver cells with the radiolabelled compounds. The rate of disappearance of radioactivity from the extracellular phase and appearance of label intracellularly were measured.

Interactions of the above compounds with serum proteins were studied in a similar way. Human serum was incubated with the labelled compounds, aliquots were withdrawn at intervals, and the proteins were precipitated with ice-cold perchloric acid. Radioactivity in the supernatant and in the washed precipitate were counted.

\section{Results}

The excretion curve (Fig. 1) shows that the gold label is excreted continuously and slowly, whereas the ${ }^{14} \mathrm{C}$ excretion is rapid initially and then very slow. Thin-layer chromatography showed that free thiomalate accounted for nearly all the ${ }^{14} \mathrm{C}$ activity in the urine except for the thiomalate disulphide, which most likely had been formed after voiding (thiomalate is readily oxidised by air at room temperature and neutral $\mathrm{pH}$ to its corresponding disulphide). Faeces contained negligible amounts of both labels after 6 hours and approximately $2.5 \%$ of each label after $\mathbf{2 0}$ hours. Analysis of expiratory air showed that thiomalate is not metabolised to carbon dioxide in the body, as less than $0.5 \%$ was recovered as radioactive carbon dioxide in the expiratory gases. Whole body analyses showed that after 6 hours approximately $50 \%$ of the thiomalate activity remained in the body, and after 20 hours about $40 \%$ of the ${ }^{14} \mathrm{C}$-label was still bound to body constituents.

The organ distribution of the labels (Table 1) showed that the blood and the kidneys in particular contained a large portion of gold label, in agreement with earlier reports. The blood thiomalate concentration, on the other hand, was remarkably low, and 6 hours after injection only about $0.1 \%$ of the thiomalate activity remained circulating. This explains the shape of the urinary excretion curve of thiomalate. As regards the blood concentration, thiomalate behaves differently from gold as well as from penicillamine, of which as much as $15-20 \%$ remained in circulation 12 hours after administration (not shown). All organs contained both thiomalate activity and gold activity as shown in Table 1. The ratio between the labels $\left({ }^{195} \mathrm{Au} /{ }^{14} \mathrm{C}\right)$ varied considerably, for example, from 80 in blood to 0.1 in the brain after 6 hours. It is apparent from the change in the ratios with time that thiomalate in general is taken up by the tissues faster than gold. The kidney and the liver contained relatively more of the thiomalate label than the other organs. The chemical form of the ${ }^{14} \mathrm{C}$ label in the organs was shown by thin-layer chromatography to consist mainly of free and protein bound thiomalate.

The low concentration of thiomalate in blood suggested a low tendency of this thiol to form mixed disulphides with serum proteins. This was confirmed in a series of in-vitro experiments, in which only a small portion of the radiolabel became bound to the

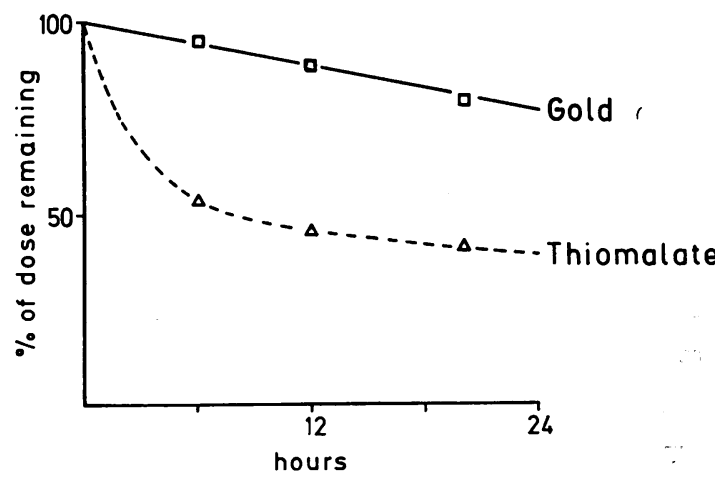

Fig. 1 Elimination of thiomalate and gold after aurothiomalate administration to mice. The animals were given the drug as double isotope labelled compound $\left({ }^{195} \mathrm{Au}-{ }^{14} \mathrm{C}\right)$ as described in the text. 
Table 1 Organ distribution of gold and thiomalate after intramuscular administration of double isotope-labelled Myocrisin to mice

\begin{tabular}{|c|c|c|c|c|c|c|}
\hline \multirow{3}{*}{ Organ } & \multicolumn{4}{|c|}{$\%$ of dose recovered $/ g$ of tissue } & \multicolumn{2}{|c|}{ Ratio Au/thiomalate } \\
\hline & After $6 h$ & & After $20 h$ & & $6 h$ & $20 h$ \\
\hline & $195 A u$ & ${ }^{14 C}$-thiomalate & $195 \mathrm{Au}$ & ${ }^{14 C}$-thiomalate & & \\
\hline $\begin{array}{l}\text { Blood } \\
\text { Kidney } \\
\text { Spleen } \\
\text { Liver } \\
\text { Brain } \\
\text { Lungs } \\
\text { Muscle } \\
\text { Skin }\end{array}$ & $\begin{array}{l}7 \cdot 9 \pm 0.3 \\
8 \cdot 9 \pm 0.8 \\
1 \cdot 7 \pm 0.1 \\
3 \cdot 2 \pm 0.3 \\
0.1 \pm 0.1 \\
4.4 \pm 1 \cdot 0 \\
0.9 \pm 0.1 \\
1.8 \pm 0.6\end{array}$ & $\begin{array}{l}0.1 \pm 0.1 \\
1.9 \pm 0.6 \\
1 \cdot 3 \pm 0.6 \\
1.8 \pm 0.4 \\
1 \cdot 1 \pm 0.1 \\
1 \cdot 2 \pm 0.1 \\
2.4 \pm 0.8 \\
2.6 \pm 0.2\end{array}$ & $\begin{array}{r}4 \cdot 4 \pm 0.4 \\
17 \cdot 1 \pm 4 \cdot 2 \\
1 \cdot 8 \pm 0 \cdot 2 \\
2 \cdot 5 \pm 0 \cdot 2 \\
0 \cdot 3 \pm 0 \cdot 1 \\
2 \cdot 7 \pm 0 \cdot 2 \\
0.6 \pm 0 \cdot 1 \\
2 \cdot 1 \pm 0.8\end{array}$ & $\begin{array}{l}0 \cdot 1 \pm 0.1 \\
3 \cdot 1 \pm 2 \cdot 6 \\
1 \cdot 1 \pm 0 \cdot 1 \\
1 \cdot 3 \pm 0.5 \\
0.3 \pm 0 \cdot 1 \\
1 \cdot 0 \pm 0.6 \\
0 \cdot 6 \pm 0.2 \\
0.8 \pm 0.2\end{array}$ & $\begin{array}{l}79 \\
4 \cdot 7 \\
1 \cdot 3 \\
1 \cdot 8 \\
0 \cdot 09 \\
3 \cdot 7 \\
0 \cdot 4 \\
0 \cdot 7\end{array}$ & $\begin{array}{l}44 \\
5 \cdot 5 \\
1 \cdot 6 \\
1 \cdot 9 \\
1 \cdot 0 \\
2 \cdot 7 \\
1 \cdot 0 \\
2 \cdot 6\end{array}$ \\
\hline
\end{tabular}

proteins (Fig. 2). After $1 \frac{1}{2}$ hours about $4-5 \%$ of the thiomalate was protein bound compared to about $10-12 \%$ in the case of penicillamine. If the incubation was carried out in the presence of oxygen, the thiols were partly oxidised, and the results then expressed the ability of the corresponding disulphides to interact with the proteins. A considerably larger portion of both compounds was then bound to the proteins (Fig. 2).
The ability of thiomalate, aurothiomalate, and penicillamine to penetrate cellular membranes was studied in a series of in-vitro experiments, with washed erythrocyte and isolated liver cells (hepatocytes) as cellular models. Fig. 3 demonstrates that Myocrisin itself did not penetrate the erythrocyte membrane. Penicillamine and thiomalate penetrated, but at a slow rate. Thus after approximately 1 hour $90 \%$ of the latter compound was still present
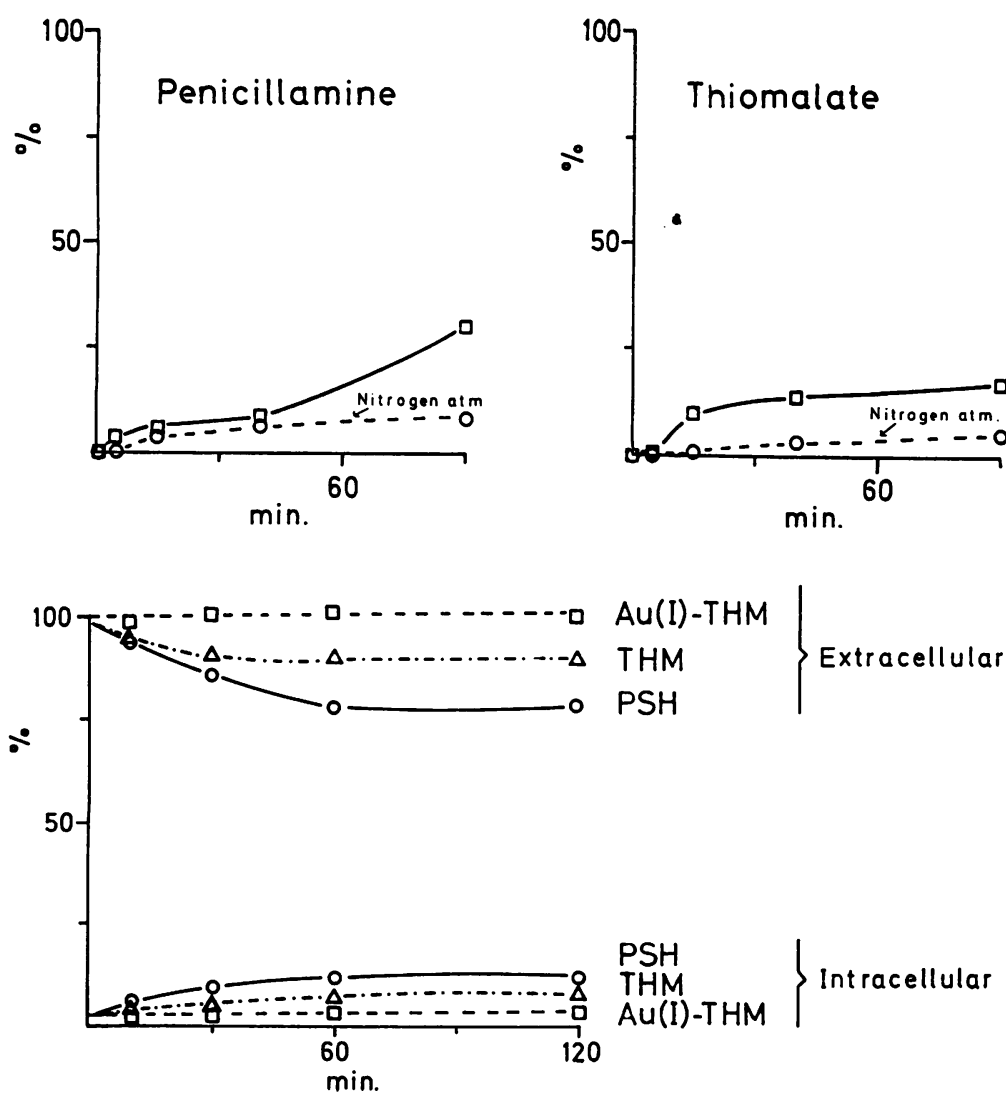

Fig. 2 Binding of penicillamine (left) and thiomalate sodium salt (right) to human serum proteins at $\mathrm{pH} 7 \cdot 4 . \mathrm{O}=$ incubated in an atmosphere of nitrogen to prevent oxidation of the thiols. $\square=$ incubation in air, oxidation not prevented.
Fig. 3 Penetration of aurothiomalate, thiomalate (THM), and penicillamin (PSH) into human erythrocytes. Disappearance of radiolabel from the extracellular phase and intracellular appearance were measured. 
in the extracellular phase and only about $5 \%$ was recovered intracellularly. The difference $(5 \%)$ was bound to the cellular surface (membrane proteins). Similar results were obtained with isolated hepatocytes as cellular model (not shown).

\section{Discussion}

The experiments described above, in which double isotope-labelled Myocrisin was administered to mice, clearly show that the gold and the thiomalate moieties separate in vivo, resulting in proteinbound gold and free thiomalate. A considerable part of the thiol is not excreted but is taken up by the tissues and the cellular membranes. Separation of the gold moiety from the thiomalate carrier also takes place in man. Thus thiomalate is found in the urine of patients receiving Myocrisin intramuscularly (Heininger et al., 1978). Owing to the high affinity of protein-SH for gold ions, a similar splitting of other gold-containing drugs like gold thioglucose (Solganol) is also likely to take place, again with release of the free thiol.

An important question to consider therefore is whether thiomalate (and thioglucose), like penicillamine, have any biological effects. They have been demonstrated by Arrigoni-Martelli and his associates in Copenhagen (Arrigoni-Martelli et al., 1978). Thiomalate and thioglucose were found to have penicillamine-like effects on delayed hypersensitivity reactions and on adjuvant arthritis.

The thiol penicillamine is known from controlled clinical trials to have a beneficial effect in the treatment of rheumatoid arthritis. Quite recently another thiol, thiopyridoxine, has also been shown in controlled trials to act as an antirheumatic drug (Camus, personal communication; Jaffe, 1978). Similar controlled trials have not yet been performed with thiomalate or thioglucose. However, in view of the results discussed above, one might speculate that at least part of the effects of Myocrisin (and of Solganol) may be due to their thiol carriers.
We are grateful to Dr W. R. Wragg and his colleagues at May and Baker, Ltd., Dagenham, England, for supplying us with radiolabelled Myocrisin and for their support and interest in our work. Dr J. Norseth, Rikshospitalet, is acknowledged for his help in preparing hepatocytes. Norske Kvinners Sanitetsforenings Forskningsfond, Norsk Hydro, and Det norske Revmatismeråd are thanked for financial support.

\section{References}

Arrigoni-Martelli, E., Bramm, E., and Binderup, L. (1978). D-penicillamine-like activity of thiols. In EBRA Symposium on Anti-inflammatory and Anti-rheumatic agents. Paris, 22 July, 1978.

Danpure, C. J. (1974). The binding of aurothiomalate to serum proteins in vitro. Biochemical Society Transactions, 2, 899-901.

Danpure, C. J. (1976). Interaction of aurothiomalate with human serum albumin in vitro. Biochemical Society Transactions, 4, 161-163.

Feltkamp, J. T. (1979). Editor, Proceedings 2nd Bertine Kooperberg Conference. To be published as suppl. to Scandinavian Journal of Rheumatology,

Heininger, J., Munthe, E., Pahle, J., and Jellum, E. (1978). Capillary column gas chromatography-mass spectrometry in studies on rheumatoid arthritis. Journal of Chromatography, 158, 297-304.

Jaffe, I. A. (1978). To be published in Proceedings 2nd Bertine Kooperberg Conference, as suppl. to Scandinavian Journal of Rheumatology.

Jellum, E., Aaseth, J., and Munthe, E. (1977). Is the mechanism of action during treatment of rheumatoid arthritis with penicillamine and gold the same? Proceedings of the Royal Society of Medicine, 70, suppl. 3, 136-139.

Lorber, A. (1977). Monitoring gold plasma levels in rheumatoid arthritis. Clinical Pharmacokinetics, 2, 127-146.

Lyle, W. H., and Kleinman, R. L., (Editors) (1977). Penicillamine at 21: its place in therapeutics now. Proceedings of the Royal Society of Medicine, suppl. 3, 70, 3-146.

McQueen, E. G., and Dykes, P. W. (1969). Transport of gold in the body. Annals of the Rheumatic Diseases, 28, 437442.

Multi-Centre Trial Group (1973). Controlled trial of D(-) penicillamine in severe rheumatoid arthritis. Lancet, 1, 275-280.

Munthe, E. (Editor). (1977). Penicillamine Research in Rheumatoid Disease. Fabritius: MSD Norway, Oslo. 